\title{
Life on the broad side: medical research
}

\author{
Richard Smith
}

Medical research in Australia is separated administratively and financially from other types of scientific research. In addition, the Medical Research Committee (MRC) is part of the broader National Health and Medical Research Council (NHMRC), which has responsibilities for giving advice on health issues beyond research and is embedded in the Department of Health and Community Services. Almost all the medical researchers whom I met liked these arrangements, which might sound inimical to many researchers from other countries.

Researchers like the structure primarily because they think that medical research-çan do better than non-medical research with its funding and because the research is firmly linked with the health community. Some others, though, including Professor David Curtis, the past president of the Australia Academy of Science, think that it would be better if the medical researchers were linked with the Australian Research Council, which distributes funds for non-medical research.

One anxiety is that some parts of science may fall between two stools, although the members of the NHMRC insist that this is not the case. Nor, they say, is there any "double dipping," whereby some categories of science might get funds from the Australian Research Council and the NHMRC. There is a liaison committee between the two councils to try to prevent these two possibilities. The NHMRC enthusiasts also insist that there is no problem with organising interdisciplinary research, which is as fashionable in Australia as in Britain and elsewhere.

The MRC is a committee of the NHMRC along with the Health Care Committee, the Public Health Committee, and the recently created Public Health Research and Development .Committee (fig 1). The NHMRC has a broad remit to advise the Commonwealth and state governments on all aspects of health, and supervising research is only one of its responsibilities.

B.117 1991:302:897-9

\section{Links beyond research}

The close links with the other parts of the health community mean that the researchers can receive inputs from lay people, clinicians, public health advocates, and the others represented on the NHMRC and its committees, which helps with setting priorities. In addition, the researchers potentially have better links to see that their discoveries are fed through into practice.

I can imagine that members of the British Medical Research Council, which is jealous of its independence, might be terrified by the thought of being a subcommittee of a much broader committee that is itself partially embedded in the Department of Community Services and Health. The NHMRC comprises a chairman appointed by the government; the chairmen of the four main committees; and nominees from the states, the universities, the Australian Academy of Sciences, the trade unions, industry, consumer organisations, and the Australian Council of Social Service. What's more, the council's meetings are held in public. To the instinctively elitist and secretive members of the British medical research establishment this might all sound frighteningly open and democratic, but all of the members of the Australian MRC with whom I spoke were thoroughly pleased with the structure and thought that it gave them the best of both worlds: they have broad political support, clear direction on the perceived needs of the community, and almost complete independence when it comes to making their research grants.

The researchers have, indeed, learnt to use the openness of the meetings to achieve their ends; thus, for instance, bodies that might be dragging their feet on issues like supporting codes of good research practice can be brought into line by the possibility of exposure to the media at a council meeting. It was the immediate past chairman of the NHMRC-John Chalmers, professor of medicine at Flinders University, Adelaide - who introduced the public meetings. He also-when chairman of the MRC-introduced the practice of sending back all referees' reports to applicants for grants. "I believe," he says, "in always being ahead of the demand for freedom of information."

The independence of the MRC - and the NHMRC - derives in large part from the independence of the members of the committees. Thus the chairpersons and members are part time and have other posts (and incomes). This has always been the case for the chairman of the MRC, but before Professor Chalmers took up his post in 1988 the NHMRC had been chaired by the head of the Department of Community Services and Health. "This wasn't as good as having an independent chairman," says Professsor Chalmers, "because the chairman might then stop developments either by saying that he couldn't do something or by saying that he could and then not devoting sufficient resources." The independence of the MRC is reinforced by the fact that it receives its money directly from the Medical Research Endowment Fund, which was set up by act of parliament in 1937; the money doesn't come through the NHMRC. Furthermoreand in contrast to the British MRC-the members of
Public Health Development Committee 


\section{High standards in medical ethics}

The Medical Research Committee has been required to be concerned about ethical issues since it started in 1937, but it was in 1982 that the Medical Research Ethics Committee was formed to advise on particular ethica issues, review institutional ethical committees, and liaise with interested bodies. The committee is chaired by Professor Ross Kalucy, dean at Flinders Medical School, and consists of two lawyers, a moral theologian, two medical scientists, a non-medically qualified scientist, and three laypeople.

Professor Kalucy told me that the committee works by guidelines rather than rules, but it has wide influence because of its job in reviewing institutional ethical committees - and in order to be accredited or receive funds from the NHMRC institutions need to have ethics committees. The central committee surveys the loca committees and visits each state each year to meet with them. The result of this system is that the local committees are much less variable in quality and performance than

the Australian MRC have much more power than the members of the secretariat, who are mostly civil servants from the health department rotating through the MRC.

\section{Debating independence}

One of the most interesting features of the NHMRC apart from its breadth is the way that it is constantly renewed and reviewed. The council and its committees are appointed for trienniums, and at the end of each triennium there is a review of the council and its achievements and failures. Sometimes this review is conducted by insiders and sometimes by outsiders. The latest review - made available to the public at the end of last year' - had contributions from both insiders and outsiders. Insiders conducted an initial review, and then the Minister for Community Services and Health, Brian Howe, appointed five outsiders to review the review.

A central feature of the review is the debate over whether the NHMRC should be separated from the Department of Community Services and Health and given statutory independence by an act of parliament. The insiders' review and almost all of the medical researchers I met were against statutory independence, but the minister and some of the outsiders are in favour - and the minister has announced his intention to go ahead with establishing the council under legislation. The researchers wait with some apprehension to see how the legislation will be drafted.

The minister argues that a body such as the NHMRC that makes statements on health issues of great import to the Australian people must be seen to be independent of the government; otherwise there may be worries about whether the statements have been compromised by political expediency. Such a body should also have direct accountability to parliament, and there should be the possibility of debating the body's annual report in parliament.

The insiders' review was against the proposal because they didn't see any problems with independence, were worried that the council would lose flexibility and contact with the "real world" of the department, and thought that costs would increaseparticularly if a completely separate secretariat was established. One of the outside reviewers noted that "the openness, representativeness, responsiveness, and accountability of NHMRC is exemplary" and that "if it isn't broken don't fix it." Many of the researchers I met were privately worried that far from increasing independence the minister's proposals would decrease it. They smell politically directed research. And the they are in, say, Britain.

The central committee also has wide influence because of the quality of its work, and it has increasingly been asked to give advice on ethical issues beyond research. It looked as if its influence might diminish when the National Bioethics Consultative Committee was established, but the new committee seems to have lost some of its influence by producing what was probably an oversophisticated report on surrogate pregnancy. The MRC committee is less legally minded and recognises, says Professor Kalucy, that "regulations don't solve social problems."

The triennial review of the NHMRC has recommended the setting up of a health ethics committee that would be a subcommittee of the NHMRC rather than simply the MRC.' It will have responsibility not just for research ethical issues but also ethical care issues arising from health care and "the largely untouched public health issues."

heavy handed treatment of the universities by the government sets what the researchers see as a poor precedent.

In a speech made to the council in November the health minister talked about the perception that the council was dominated by doctors and referred to " $\mathrm{my}$ view that our research horizons need to be broadened to take into account the social factors that both give rise to and will play an important part in coping with Australia's health problems." $\mathrm{He}$ also said: "We must find ways of ... encouraging the partnerships between medical science and industry" and later talked of "targeting and coordinating the strengths of the different funding bodies."

The researchers must wait to see the legislation and how it will be implemented. They are anxious.

\section{Setting strategy}

The minister and the insiders' review were keen that both the NHMRC and the MRC should set a strategy with priorities, and the new chairpersons of the council (Dr Diana Horvath, director of health services in the eastern Sydney area for the New South Wales Department of Health) and the MRC (Professor Ian McCloskey, professor of physiology at the University of New South Wales) are getting ahead. Dr Horvath intends that the council should set its priorities at the very beginning of the triennium, and one priority will quite clearly be the environment and health. Others suggested by the minister are the health of Aborigines and homeless young people, the health problems of aging, the cost effectiveness of new medical technologies, and the ethical issues thrown up by those technologies. The minister wrote in a letter to Professor Chalmers: "While I accept that the NHMRC is now much more closely aligned with the community than it has been in the past, I consider that more can be done in this regard." $\mathrm{He}$ also wrote: "I am mindful of comments from a wide range of people that NHMRC research activities and priorities may not fully reflect current community needs and concerns."' Nevertheless, the minister told me that he is only making suggestions-he is not insisting that they become priorities.

The MRC already has a draft strategy that covers promoting excellence in Australian research, ensuring that research is carried out into the major health problems affecting Australians, providing training and career opportunities, and encouraging the commercialisation of the benefits of research. But there is now to be a standing research strategy committee that will conduct an analysis of the burden of health problems 


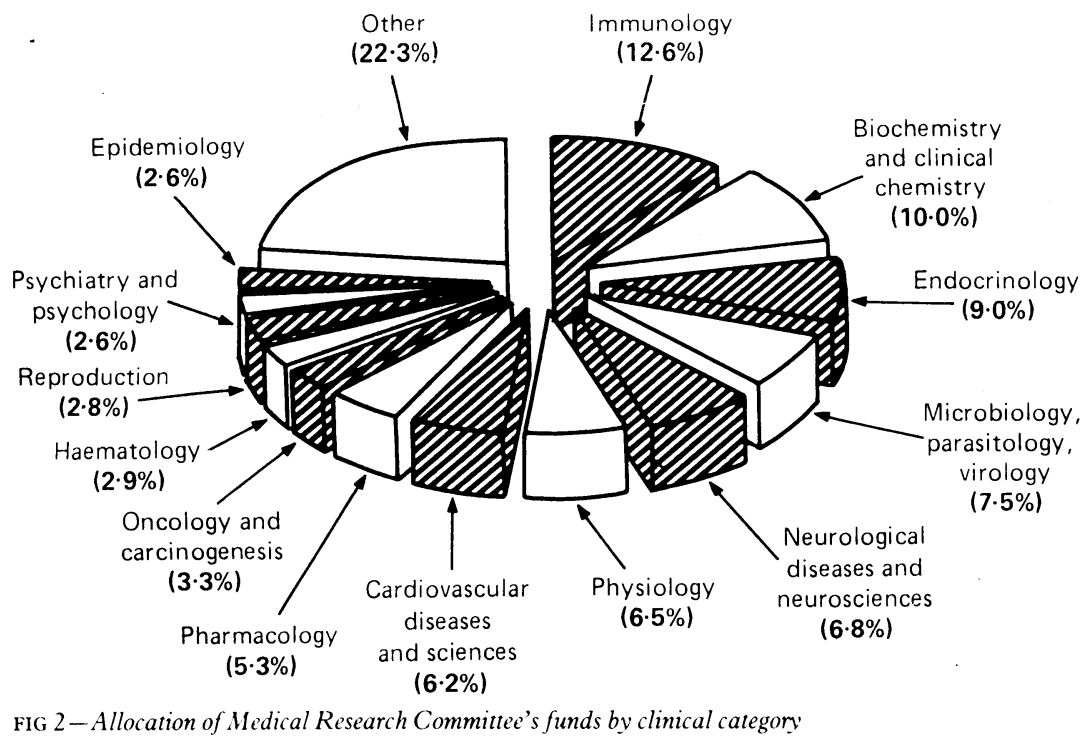

among Australians. Professor McCloskey is confident that there will be a close match between the problems and the research. Indeed, the research evaluation management committee has already conducted an analysis of where the MRC spends its money and concluded that " $46 \%$ of funds support research which addresses major health problems which have been identified in the Health Targets and Implementation (Health for All) Committee." At least a quarter of the money goes towards funding basic research, and the committee points out that much of this may eventually have an impact on the diseases that kill Australians. These analyses that attempt to link research funding to category of disease are always open to dispute, but figure 2 shows the results.

\section{Encouraging research in priority subjects}

Between 1979 and 1989 the discipline that received the most money was-as in Britain-immunology. This reflects both worldwide scientific fashion and the particular strength of Australia in immunology, but generally the NHMRC does seem to have effective mechanisms of ensuring that research is done in what are identified as priority subjects. Because of the NHMRC's broad representation and close links with the health department both it and the MRC are in a strong position to identify priorities. Those identified for 1989 were aging, AIDS, addictive behaviour, early stages of alcohol abuse, Aboriginal health, public health, and rehabilitation medicine. ${ }^{+}$For 1991 aging has been removed and asthma, behavioural medicine, environmental toxicology, health care evaluation, and menopausal health have been added. Politicians in all countries sometimes imagine that you simply identify a priority and then throw money at it to make progress; researchers, meanwhile, recognise that you must build up scientific strength in the subject.

Thus one part of the MRC's strategy is to encourage training-often overseas-in priority subjects. A second part of the strategy is the special initiative grant. These grants are awarded for grant proposals submitted in the usual way but that fall just below the cut off point for funding (see next article for a description of the peer review system). In 1989 the council awarded 40 such grants for a total of $\$ \mathrm{Al} \cdot 26 \mathrm{~m} .^{+}$ In addition, about 100 grants in priority subjects were awarded in the normal way - that is, they came above the cut off point. The hope is that after a few years of special initiative funding the subject will be built up to such a strength that it can gain funding in open competition. This has not happened with Aboriginal health, which seems to have been a priority for as long as anybody can remember.

Another strategy that the MRC uses for encouraging research in priority subjects is to establish special research units. Directors with particular skill in the subject are recruited-often from overseas-and they are then entrusted with attracting and training other researchers. In 1989 the council was funding six such units-for social psychiatry, epidemiology and preventive medicine, road accidents, addiction, schizophrenia, and clinical trials. ${ }^{+}$The council is now establishing a unit in environmental toxicology.

The final strategy for encouraging priority research of has been the establishment alongside the MRC of the Public Health Research and Development Committee. The health minister is particularly keen on public health research and is pushing the NHMRC to go faster with developing a programme "which is both excellent and relevant to Australia's emerging needs." The committee was set up five years ago and has had what the annual report calls "a somewhat slow start." It disbursed $\$ \mathrm{~A} 4 \mathrm{~m}$ in its first four years but $\$ \mathrm{~A} 3.8 \mathrm{~m}$ in 1990. It funds programmes and project grants and is onow setting up an interviewing process similar to that used by the MRC. It has also funded a health services evaluation unit in Melbourne. Professor McCloskey's hope is that eventually public health researchers will be able to compete with basic and clinical researchers and that the Public Health Research and Development Committee could then be absorbed into the MRC.

\section{Conclusion}

Medical research in Australia has many features that might be worth other countries copying. The research community has done well with using sophisticated political strategies to achieve increases in funding (see previous article). Moreover, the fact that the MRC is embedded in a structure that advises Commonwealth and state governments on all aspects of health has meant both that the research community is more in touch than the research community in some other countries with the priorities of health providers and the public and that the channels for feeding back the results of research are well developed. The council has also done well with important issues-like ethics 8 (see box) and good scientific practice - that lie between the researchers and the public.

The system of regular review-sometimes by $N$ insiders and sometimes by outsiders-has much to recommend it for any institution and has undoubtedly helped the NHMRC develop, particularly in setting strategy and priorities. Now a move is afoot to give the council statutory independence of the government: paradoxically the government is pushing the move, while researchers are suspicious that the move may mean less independence and greater costs.

1 Revieat of the National Health and Medical Research Council 1990. Canberra: NHMRC, 1990.

2 Lumbers ER. Report on the NHMRC triennial review 1990. In: Review of the National Health and Medical Research Council 1990. Canberra: NHMRC, 1990.

3 Research Evaluation Management Committee. Allocation of resources to discipline 1979-89. A report to the Medical Research Commiuee of the National Health and Medical Resurch Council Canherra: Australian Government Printing Service. 1990. National Health and Medical Research Council. Medical research 1989. Canberra: Australian Government Printing Service, 1990. 